\title{
Contamination of Organic Sulfur Compounds in Marine Products
}

(Received November 24, 1976)

\author{
Akio NaKamura and Takashi Kashimoto \\ (Osaka Prefectural Institute of Public Health: \\ 3-69, Nakamichi 1-chome Higashinari-ku, Osaka)
}

\begin{abstract}
Authors selected sulfur compounds usually contained in oil as indicator for the study of oil pollution in marine products.

It was found by FPD-GC analysis that marine products, especially fresh oyster contains similar type of sulfur compounds as found in crude oil. Sulfur compounds contained both in crude oil and oyster were isolated by the combination of two different chromatography and identified as dibenzothiophene derivatives.

Thus organic sulfur compounds are considered to be a good parameter for oil pollution in marine products.

This finding suggestes that these contamination of oil components in oyster are due to oil spill or dump out.

As an another method for studying oil pollution or spill, high pressure liquid chromatography (HPLC) technique appears to be also applicable for the comparison of heterocyclic aromatic compounds such as dibenzothiophene derivatives isolated from different sources.
\end{abstract}

\section{Introduction}

Petroleum oil contamination of estuary of coasts and marine products have long been studied by the detection of $n$-paraffins ${ }^{1)}$ and polyaromatic hydrocarbons ${ }^{2)}$.

Since the accidental leakage of C-crude oil to Seto Inland Sea in 1974, authors have investigated method of analysis of petroleum components in marine products ${ }^{3}$.

Cahman et $a ._{.}{ }^{4)}$ reported that toxic substance, 3,4-benzpyrene, was highly concentrated in oyster. And Neff et al. ${ }^{5)}$ established the method of detection of naphthalene and alkylnaphthalenes in marine animals by UV spectrometric analysis.

However, identification and determination of certain heterocyclic compounds such as organic sulfur compounds in marine products are considered to be difficult because of the lack of authentic standards and their minor existance in petroleum oil. ${ }^{6)}$

In our previous investigations, we found and reported ${ }^{7)}$ contamination of organic sulfur compounds in oyster and in some other kind of fish and also that the FPD-gas chromatographic pattern of oyster extract was very simillar to that found in C-crude oil. This fact reveals the possibility that sulfur compounds can be utilized as a parameter of oil pollution.

In this paper, useful analytical methods of sulfur compounds in marine products were described and their major components isolated both from crude oil and from oyster were identified by gas chromatography-mass spectrometry computer system.

Application of liquid chromatography for analysis of sulfur compounds in crude oil and oyster extracts was also presented.

1. Reagents

All solvent used are pesticide or PCB analysis grade from Wako Pure Chemical Industries, Ltd. Dibenzothiophene, one of the authentic standards of sulfur compounds is a special grade obtained from Wako Pure Chemicals and dissolved in hexane for gas chromatography (GC) or in methanol for the liquid chromatography (LC) analyses.

\section{Instruments}

2.1. Gas Chromatography (GC)

A Shimadzu 4B-PF gas chromatograph equipped with $394 \mathrm{~nm}$ optical filter (FPD-GC) was 
used for analyses of sulfur components. A glass column $(2 \mathrm{~m} \times 3 \mathrm{~mm}$ i.d. $)$ packed with $2 \%$ OV17 on Gaschrom $\mathrm{Q}(80 / 100)$ was used. Column temperature was at $210^{\circ} \mathrm{C}$, in jector and detector at $225^{\circ} \mathrm{C}$. Gas flows are as follows: air, $\mathrm{H}_{2}$; $22 \mathrm{ml} / \mathrm{min}$ and $\mathrm{N}_{2} ; 40 \mathrm{ml} / \mathrm{min}$.

2.2. Gas Chromatography/Mass Spectrometry (GC/MS)

A JOEL gas chromatograph (JGC-20K) equipped with a glass column $(2 \mathrm{~m} \times 2 \mathrm{~mm}$ i.d.) packed with $3 \%$ OV-17 on Gaschrom Q $(80 / 100)$ was connected to high resolution mass spectrometer system (JMS 01SG-2, JOEL) for analysis of components.

2.3. High Presure Liquid Chromatography (HPLC)

Du Pont 830 with a stainless column $(1 \mathrm{~m} \times$ $2.1 \mathrm{~mm}$ i.d.) packed with Permaphase $\mathrm{ODS}$ was employed. Methanol/distilled water $(70 / 30, \mathrm{v} / \mathrm{v})$ was used as an eluent and its flow rate was 1 $\mathrm{ml} / 3 \mathrm{~min}$ at $500 \mathrm{psi}$; temperature, room temp.; detector, $254 \mathrm{~nm}$.

\section{Material}

C-crude oil was obtained from Mitsubishi Oil Company Ltd. via National Institute of Health. This oil designated as the same as that spilled out in Dec. 1974 at Mizushima district,
Okayama Prefecture. Oyster samples were collected from Hiroshima where those were marketed.

\section{Procedure}

\section{Sulfur Compounds from C-crude Oil}

The procedure for analysis was outlined in Scheme 1.

C-crude oil (4g) was chromatographed by an alumina column (Merck, 1\% water addition, $500 \mathrm{~g}$ ) and eluted stepwisely as shown in the Scheme with hexane-diethyl ether. Most of sulfur compounds in crude oil were found to be collected in $10 \%$ ether in hexane ( $\mathrm{v} / \mathrm{v})$ fraction upon analyzing with FPD-GC. This fraction was subsequently chromatographed with an alumina column (Merck, Grade-II III, activated at $130^{\circ} \mathrm{C}$ for $1 \mathrm{hr}$ and deactivated with $1 \%$ water addition, $10 \mathrm{~g})$ with hexane elution $(100 \mathrm{ml})$. The hexane eluate was concentrated to $5 \mathrm{ml}$ and finally applied to a silica gel column (Merck, activated at $130^{\circ} \mathrm{C}$ for $4 \mathrm{hr}$ and deactivated with $3 \%$ water addition, $10 \mathrm{~g}$ ). The yield in the final hexane $(100 \mathrm{ml})$ eluate was $116 \mathrm{mg}$. This fraction was analyzed by FPD-GC and GC/MS computer system (high resolution).

\section{Isolation of Sulfur Compounds from Oyster} Fresh oyster $(50 \mathrm{~g})$, blotted into pieces, was

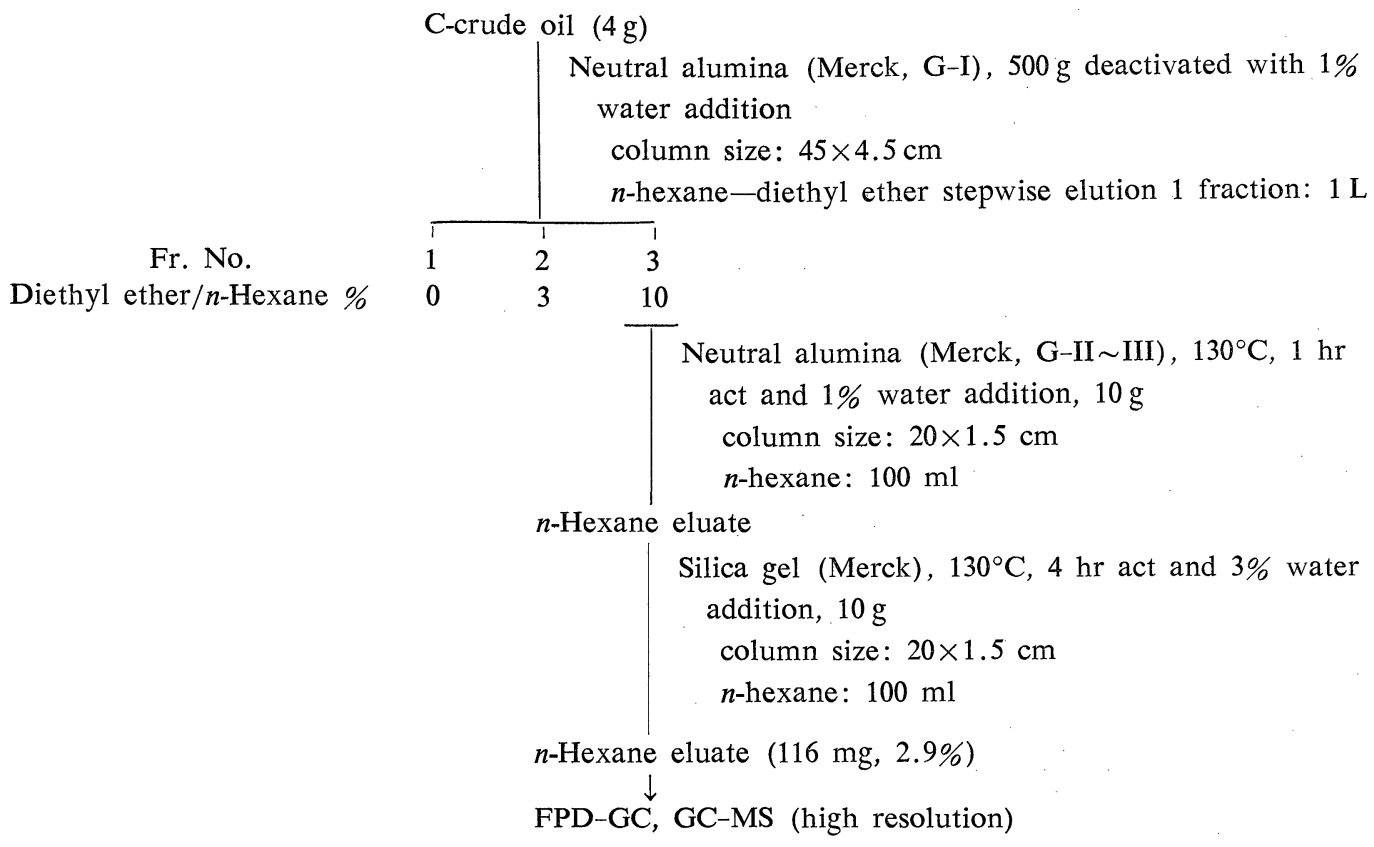

Scheme 1. Procedure for the separation of sulfur compounds from C-crude oil. 


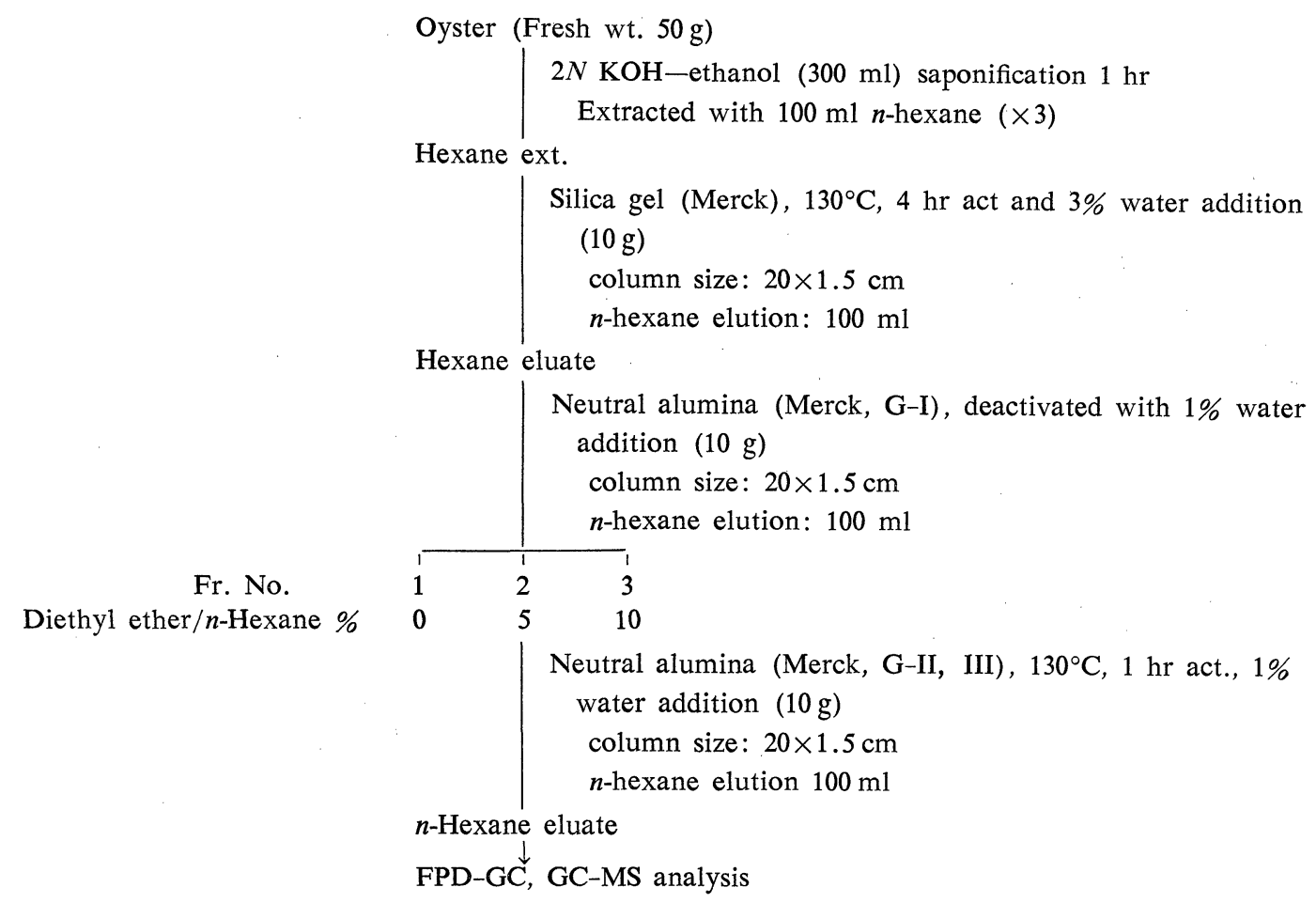

Scheme 2. Procedure for the separation of sulfur compound from oyster

saponified with $2 N$ potassium hydroxide solution -ethanol $(300 \mathrm{ml})$ for $1 \mathrm{hr}$ as outlined in Scheme 2. After saponification and addition of same portion of water, this phase was extracted with hexane $(100 \mathrm{ml})$ three times. Hexane extract was concentrated and chromatographed by a silica gel column (activated at $130^{\circ} \mathrm{C}$ for $4 \mathrm{hr}$ and $3 \%$ water addition, $10 \mathrm{~g}$ ) with $100 \mathrm{ml}$ hexane as eluting solvent. The eluate was again chromatographed by a neutral alumina (Merck, Grade-I, deactivated with $1 \%$ water addition, $10 \mathrm{~g}$ ) stepwisely as shown in the Scheme with diethyl ether-hexane $(100 \mathrm{ml}$ each $)$. Sulfur compounds were eluted with both $5 \%$ and $10 \%$ ether in hexane fraction. The latter fraction had relatively less disturbance on FID-GC, therefore this fraction was finally chromatographed by an alumina (Merck, GradeII III, activated at $130^{\circ} \mathrm{C}$ for $1 \mathrm{hr}$ and deactivated with $1 \%$ water addition, $10 \mathrm{~g}$ ). The final hexane eluate was analyzed by FPD-GC and GC/MS for identification of sulfur compounds comparing with those in C-crude oil.

\section{HPLC Analysis of C-crude Oil?}

\subsection{C-crude Oil}

Sulfur compounds fraction in final hexane solution $(5 \mathrm{ml})$ obtained from C-crude oil as mentioned above was reextracted with methanol $(5 \mathrm{ml})$ and assayed by HPLC.

\subsection{Oyster Extract}

Hexane fraction obtained after silica gel column chromatography described above was concentrated and reextracted with methanol (5 $\mathrm{ml}$ ) for the analysis. Injection volumes were $10 \mu 1$ in both cases.

\section{Results and Discussion}

\section{Sulfur Compounds in C-crude Oil}

Figure 1 shows the comparison of FPD-gas chromatograms of $\mathrm{C}$-crude oil and the fraction of sulfur compounds separated from C-crude oil by the procedure appeared in Scheme 1 .

Most of the peaks were recovered perfectly except a minor peak, No. 2. This fraction, therefore, was measured by GC/MS for the identification of the component. Figure 2 shows total ion current chromatograms of sulfur compounds derived from $\mathrm{C}$-crude oil. This pattern is very close to FPD-GC in C-crude oil.

Identified components were described in Table 1.

From this analysis, only one hydrocarbon 


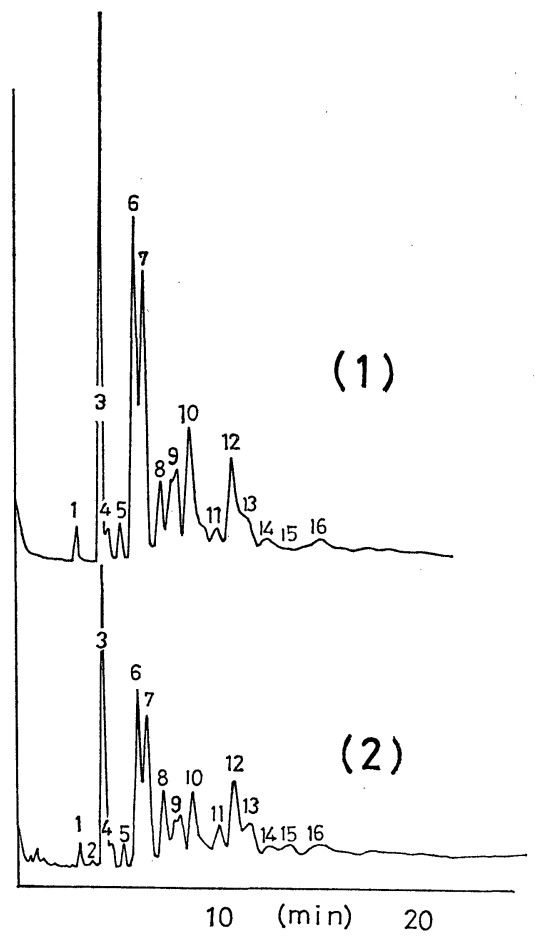

Fig. 1. Comparison of FPD gas chromatograms between C-crude oil and the fraction of sulfur compounds separated from C-crude oil: (1), after separation; (2), C-crude oil

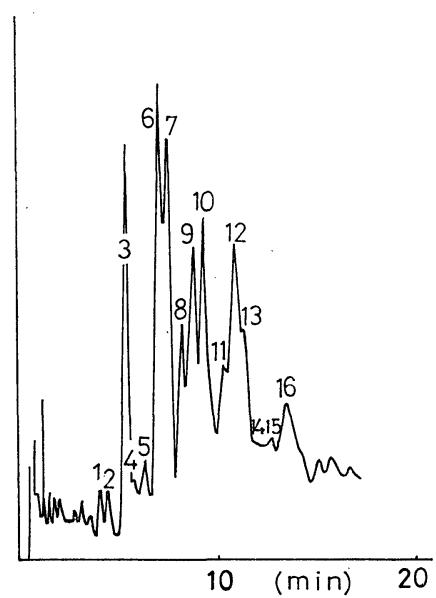

Fig. 2. Total ion current chromatogram of sulfur compounds fractionated from $\mathrm{C}$-crude oil

$\left(\mathrm{C}_{14} \mathrm{H}_{10}\right)$ was recognized as anthracene by the same retention time as an authentic standard on GC. All other compounds contain one sulfur atom and seem to be alkyl-substituted series
Table 1. Determination of Components in the Fraction of Sulfur Compounds by High Resolution Mass Spectrometer

\begin{tabular}{c|c|l} 
Peak No. & $m / e$ & \multicolumn{1}{c}{$\begin{array}{c}\text { Calculated } \\
\text { formula }\end{array}$} \\
\hline 1 & 187 & $\mathrm{C}_{12} \mathrm{H}_{8} \mathrm{~S}$ \\
2 & 178 & $\mathrm{C}_{14} \mathrm{H}_{10}$ \\
$3 \sim 5$ & 198 & $\mathrm{C}_{13} \mathrm{H}_{10} \mathrm{~S}$ \\
$6 \sim 8$ & 212 & $\mathrm{C}_{14} \mathrm{H}_{12} \mathrm{~S}$ \\
$9 \sim 11$ & 226 & $\mathrm{C}_{15} \mathrm{H}_{14} \mathrm{~S}$ \\
$12 \sim 14$ & 240 & $\mathrm{C}_{16} \mathrm{H}_{16} \mathrm{~S}$ \\
15,16 & 254 & $\mathrm{C}_{17} \mathrm{H}_{18} \mathrm{~S}$
\end{tabular}

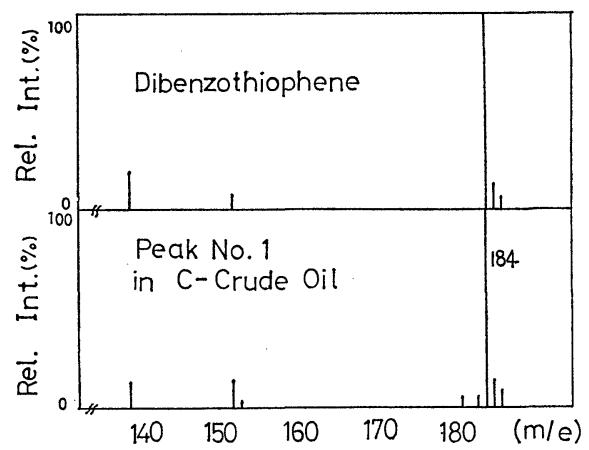

Fig. 3. Mass spectra of peak No. 1 in C-crude oil and dibenzothiophene

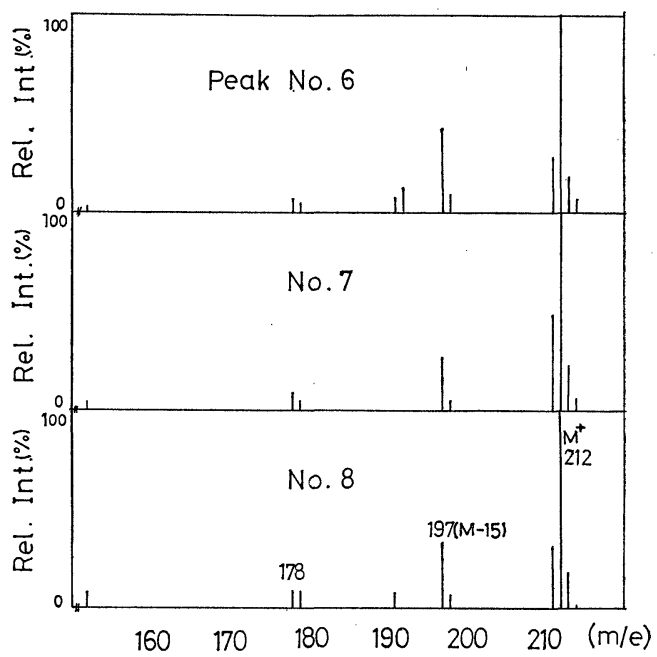

Fig. 4. Mass spectra of peak No. 6, 7 and 8 in C-crude oil

having a fundamental structure, $\mathrm{C}_{12} \mathrm{H}_{8} \mathrm{~S}$, and increasing- $\left(\mathrm{CH}_{2}\right)$-units in their structures. From the authentic standard, peak No. 1 was confirmed 


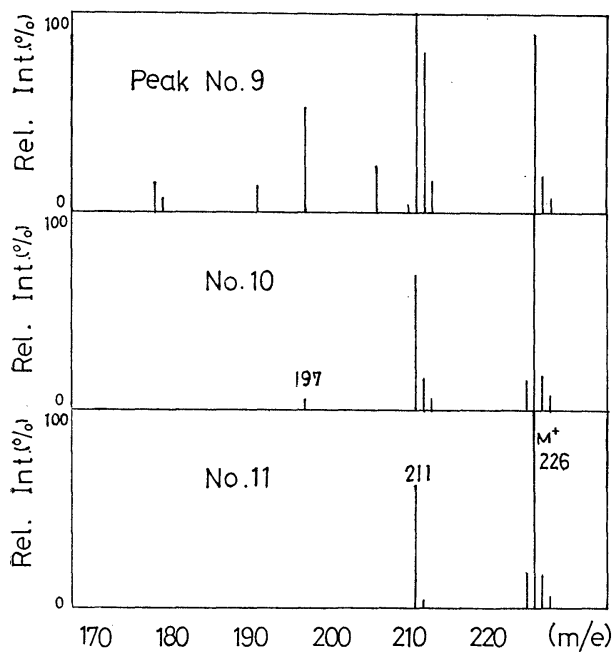

Fig. 5. Mass spectra of peak No. 9, 10 and 11 in C-crude oil

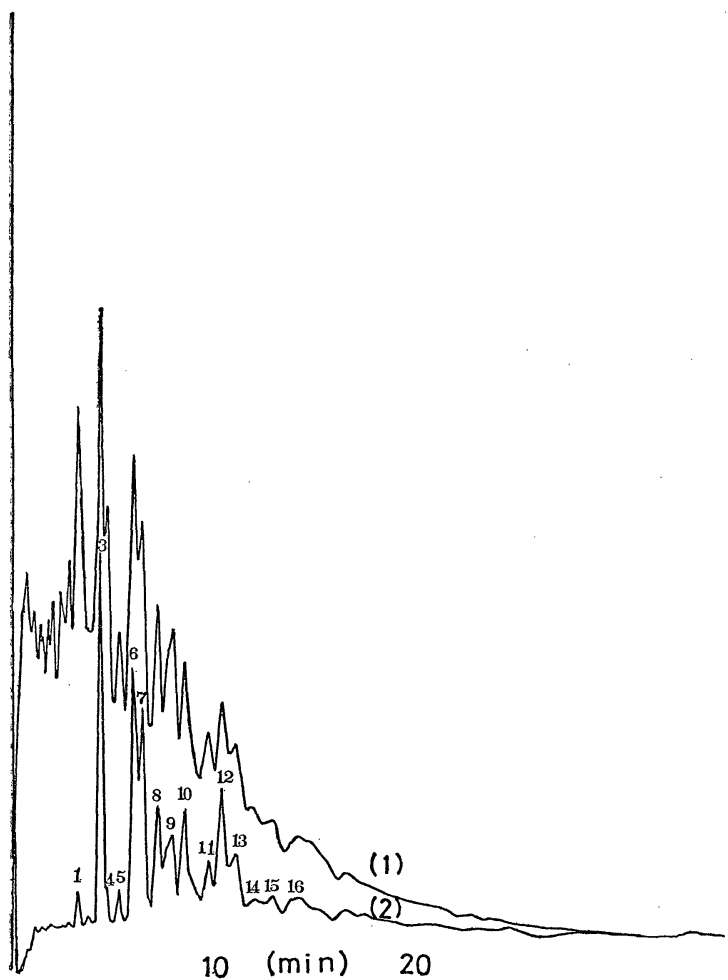

Fig. 6. FPD gas chromatograms of fractionated sulfur compounds from oyster (1) and C-crude oil (2)

to be dibenzothiophene.

Figure 3 shows mass spectra of peak No. 1 and dibenzothiophene. Figure 4 and 5 show

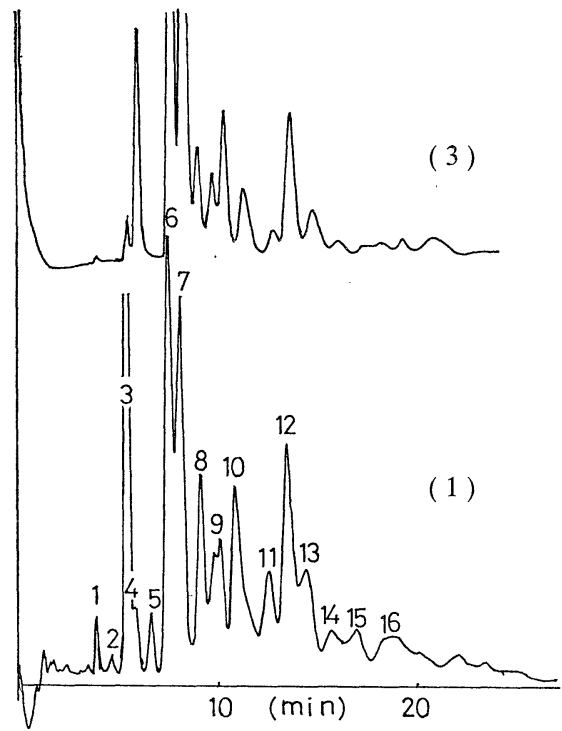

Fig. 7. Comparison of FPD gas chromatograms of fractionated sulfur compounds from $10 \%$ diethyl ether in hexane fraction in Fig. 7(1) and C-crude oil (2)

fragmentations of peak No. $6 \sim 8$ and No. $9 \sim 11$. These compounds have no significance of the fragmentation each other, that is, the highest $\mathrm{M}^{+}$and $\mathrm{M}^{+}-15$.

\section{Sulfur Compounds in Oyster Extracts}

As reported in the previous paper, silica gel chromatographic separation was conventionally used for isolation and assay of sulfur compounds. Figure 6 shows FPD-gas chromatograms of sulfur compounds from oyster and C-crude oil separated by silica gel column. This reveals that sulfur peaks from oyster having rather longer retention time show fairly good accordance with those isolated from C-crude oil. This fraction was further chromatographed on alumina as described in Scheme 2.

The final hexane eluate in the procedure was analyzed by FPD-GC and GC/MS.

Figure 7 shows the comparison of FPD-chromatograms of fractionated sulfur compounds from oyster (1) and C-crude oil (2). The earlier peaks in the chromatogram in Fig. 7 were almost eluted out in the proceeding $5 \%$ diethyl ether in hexane fraction.

Figure 8 shows total ion current chromatograms of final extracts of oyster and C-crude oil, in which mass spectral analyses of each peak and 


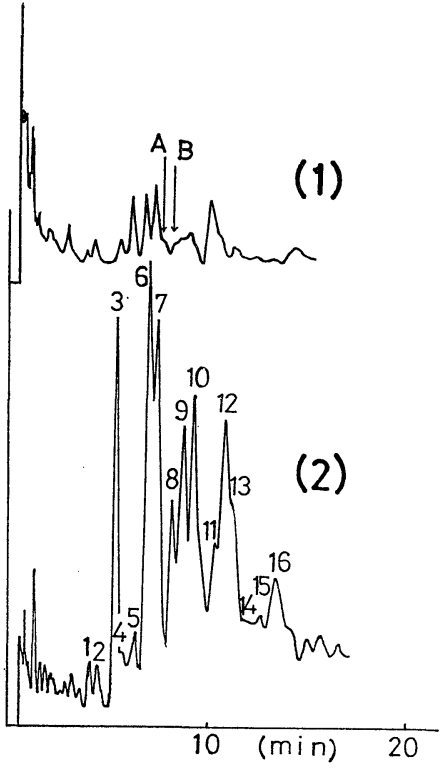

Fig. 8. Total ion current chromatograms of sulfur compounds fractionated from oyster extract (1) and C-crude oil (2)

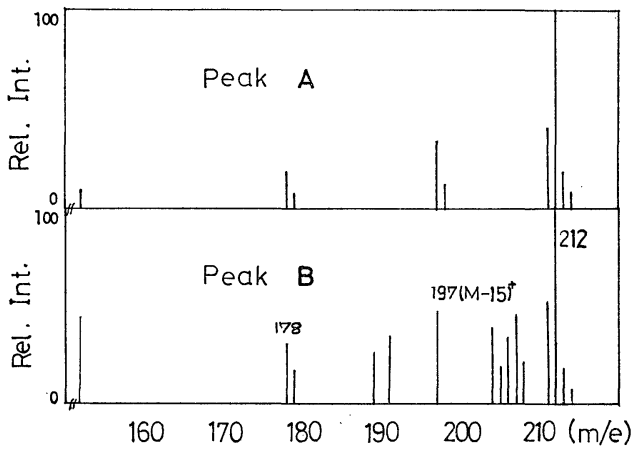

Fig. 9. Mass spectra of peak No. A and B from oyster extract

shoulder were performed. Peak A and Peak B among the several peaks in an ion current chromatogram from oyster were coincide with peak No. 7 and No. 8 in crude oil from GC/MS fragmentation patterns (Fig. 9). This designated that majority of substituted dibenzothiophene derivatives in crude oil were also found mostly in fresh oyster samples. It is possible to say that these contaminants came from oil spill or from environment pollution by dump out of factories and accumulated in these organisms.

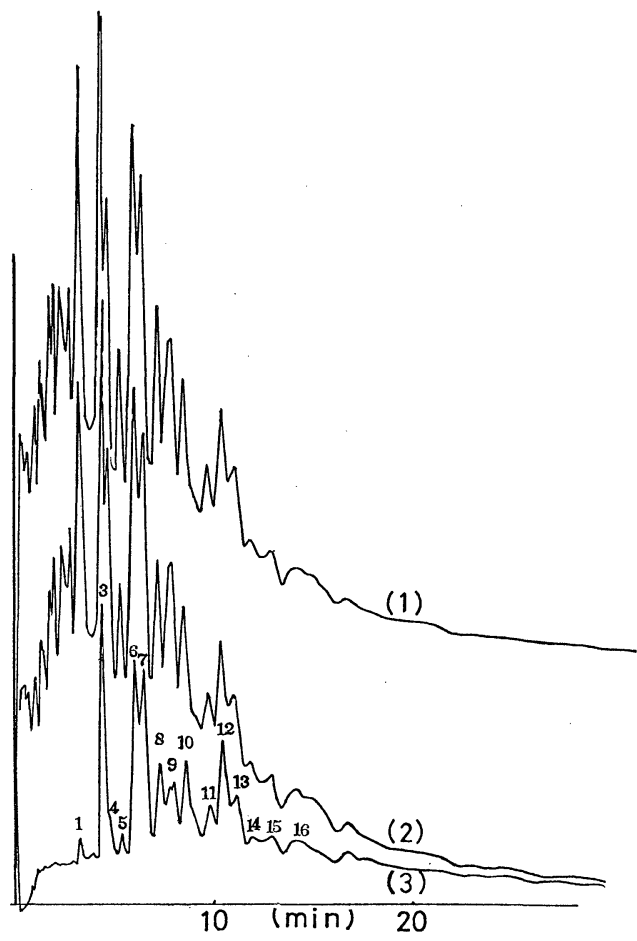

Fig. 10. FPD gas chromatograms of oyster extracts (1) and (2) fractionated on silica gel chromatography after saponification and that of C-crude oil (3).

These oyster samples were obtained from different places both in Hiroshima Prefecture.

3. HPLC Analysis of Sulfur Compounds in Crude Oil and Oyster

There seems to be a number of heterocyclic hydrocarbons such as dibenzothiophene in the extract of C-crude oil identified by GC/MS analysis. This indicates that UV or fluorescence spectroscopy has much sensitivity for the analysis of these compounds. Therefore, as an another method for the comparison between components in oil and the extracts from marine products, the application of HPLC ( $254 \mathrm{~nm}$ : detector) was suggested to be valuable.

Oyster extract after silica gel column shown in FPD-gas chromatogram of Fig. 10 indicate that even though they differ in harvesting places in Hiroshima Prefecture, both are in good accordance with each other. These hexane eluates were reextracted with methanol and injected to HPLC.

Figure 11 shows the comparative chromatograms 


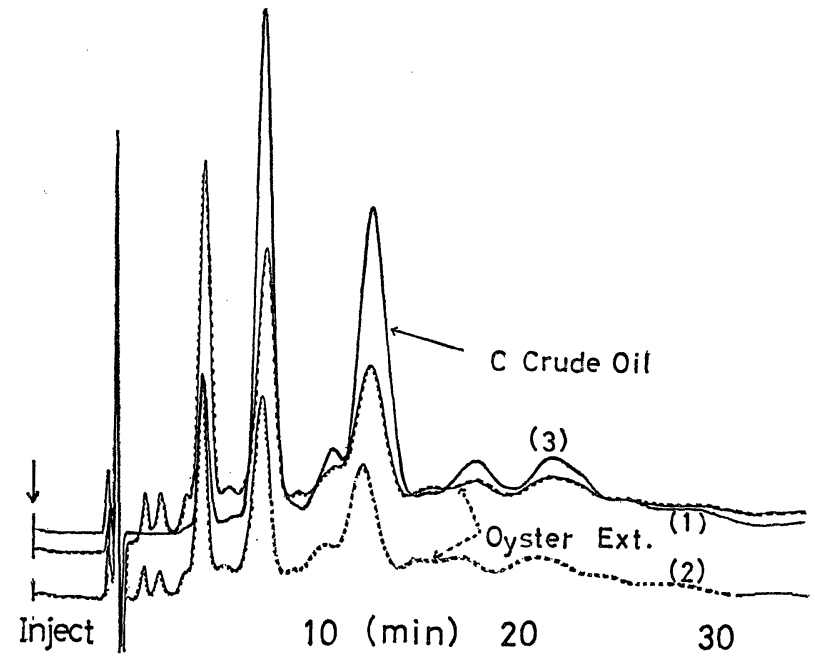

Fig. 11. Comparison of liquid chromatograms between extracts from oyster (1), (2), which came from different harvesting places both in Hiroshima Prefecture and C-crude oil.

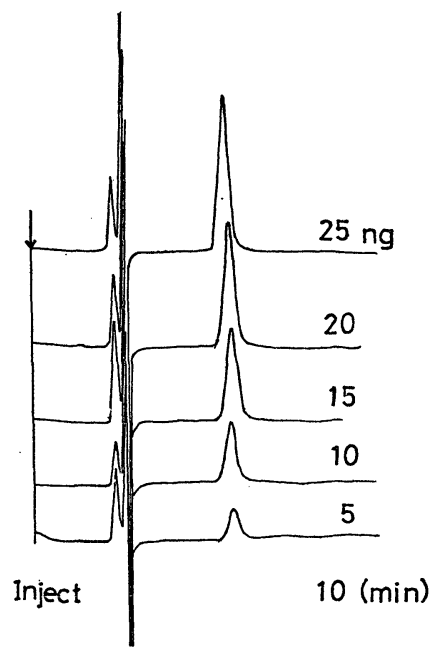

Fig. 12. Liquid chromatogram of dibenzothiophene

of HPLC analyses on crude oil extract and the extracts from oyster. There shows a good accordance each other in the LC chromatograms.

4. Sensitivity to HPLC of dibenzothiophene

In the chromatogram of Fig. 11, dibenzothiophene seems to be situated at the shoulder peak in the first higher peak of the three. Figures 12, 13 show the calibration figure of dibenzothiophene on $254 \mathrm{~nm}$ analysis. As shown in Fig. 13, linear calibration curve would make determination of concentration possible and easier than FPD-GC, which has relation to square

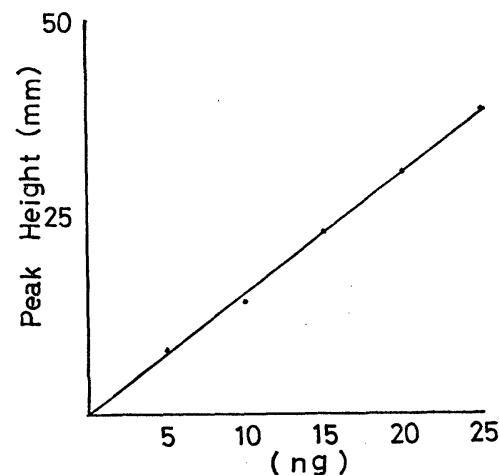

Fig. 13. Calibration curve of dibenzothiophene by $\mathrm{LC}$ analysis

amounts of concentration.

There becomes a serious problem among marine products that an offensive odour in fishes observed at the vicinity of oil refining companies. ${ }^{8)}$ It was mainly identified that benzene derivatives such as toluene, xylene were the source of odour. ${ }^{9)}$

It is, however, undetermined whether sulfur compounds such as dibenzothiophene derivatives also cause such odour or not yet.

Ishida et al., ${ }^{10)}$ reported by the experiment of transfer of crude oil components in eel that low molecular sulfur compounds in crude oil were easily transferred to eel and excreted again rapidly back to clean water.

Oil pollution of sea water in the global 
ecological system is mainly caused by oil spill or dump out of industrial wastes. Nowadays it becomes an urgent subject to monitor these contaminants transferred via marine products to man. Therefore, hereafter we believe that use of these parameter of oil pollution such as sulfur compounds, $n$-paraffins, and other polyaromatic hydrocarbons is necessary for systematically analysis and monitoring of oil pollution.

As for analytical techniques, Bentz ${ }^{11)}$ summarised many monitoring techniques for identification of oil spill, however, there are less reports about combined methods of analytical techniques with biological ones such as bioassay.

The toxicity of dibenzothiophene derivatives and other organic sulfur compounds in crude oil is not clarified yet. The stability of these substance in the environment is also remained obscure. Further investigations are necessary for the toxicological implications of sulfur compounds derived from fuel oil.

\section{Acknowlegments}

The authors are grateful to Dr.M. Uchiyama at National Institute of Health for his generous advices for this research. They are also indebted Dr.Y. Itagaki and his colleagues at JOEL for high resolution mass analyses.

\section{References}

1) Brown, R.A., Huffman, H.L., Jr.: Science,
191, 847 (1976).

2) Andelman, J.B., Suess, M.: Bull. Wld. H1th. Org., 43, 479 (1970).

3) Scientific Fisheries Soc. Japan (ed.): "Oil Contamination and Fishery Organisms," Scientific Fisheries series No. 16, Koseishakoseikaku, Tokyo, 1976.

4) Cahnman, H.J., Kuratsune, M.: Anal. Chem., 29, 1312 (1957).

5) Neff, J.M., Anderson, J.W.: Bull. Environ. Contam. Toxicol., 14, 122 (1975).

6) Thompson, C.J., Coleman, H.J., Hopkins, K.L., Rall, H.T.: "Sulfur Compounds in Petroleum," Hydrocarbon Analysis, ASTM STD 389, Am. Soc. Testing Mats., 1965, p. 329.

7) Nakamura, A., Murakami, Y., Miyata, H., Hori, S., Maeda, K., Kashimoto, T.: J. Food Hyg. Soc. Japan, 16, 282 (1975).

Murakami, Y., et al.: Proc. Osaka Prefectural Institute of Public Health, 6, 83 (1975).

8) Motohiro, T., Miyashita, K.: Journal of Environmental Pollution Control, 8, 1080 (1972).

9) Ogata, M., Ogura, T.: Water Research, 10, 407 (1976).

10) Ishida, T., et al.: Proc. Okayama Prefectural Institute of Health, 23, 27 (1976).

11) Bentz, A.P.: Anal. Chem., 48, 454 (1976). 